able number of molecules the atoms are held together mainly by Van der Waals forces. The reader may also come to false conclusions concerning the internal field, as the Clausius-Mosotti equation is given far too much prominence. Although it is pointed out that there are some objections to this equation and the alternative Onsager formula is also discussed, nevertheless many readers may get the impression that the validity of the Clausius-Mosotti formula is much wider than it actually is. This idea has led to many mistakes in the past and it should be discouraged.

Apart from minor criticisms of this type, a great variety of readers will find the book instructive and useful. There is every reason for hoping that the author will meet with considerable success in his main aim, namely, in helping the physicist, chemist and electrical engineer to understand one another and in making them interested in each other's work.

The second book, "Dielectric Materials and Applications", is based on papers piesented at a symposium. It starts with a theoretical introduction by von Hippel which, on the whole, is a very much shortened version of the contents of the first book. The rest of the second book, consisting of papers by twentyone different contributors, deals with a great variety of practical aspects connected with dielectrics, including measuring techniques, dielectric materials used in all sorts of electrical equipment and devices, from power cables to memory devices, and there are also three papers on the dielectric requirements of the American army, navy and air force. The book also contains very extensive tables on dielectric data. Anybody who wants to acquaint himself with the problems arising in the practical applications of dielectrics will find this book an excellent introduction to the subject.

B. SzIGETI

\section{APPLIED SOLAR ENERGY}

\section{Proceedings of the World Symposium on Applied Solar Energy}

Phoenix, Arizona, November 1-5, 1955. (Sponsored by The Association for Applied Solar Energy, Stanford Research Institute, University of Arizona.) Pp. 304. (Melno Park, Calif. : Stanford Research Institute, 1956. Copies available from the Association for Applied Solai Energy, Phoenix.) 5 dollars.

THE scope of this first World Symposium on Applied Solar Energy has already been described in some detail in Nature $(177,110 ; 1956)$, and in reviewing the proceedings only brief mention will be made of the contents. The volume consists of twenty. four main papers delivered at the Phoenix Conference, and includes the opening remarks by Lewis $W$. Douglas, the weleoming luncheon address by Sir Edward Bullard, and the banquet address by John Jay Hopkins, "Towards a New Heaven and a New Earth". There is also a record of the panel discussions on solar house heating, architectural problems, and the future of applied solar energy. A description of the Solar Fngincering Exhibition is included.

The geneial extent of applied solar energy research is now well known and includes low-grade heat applications such as water and house heating, cooking, water distillation, high-temperature solar furnaces, mechanical and electrical power, refrigeration, chemical energy conversion and artificial cultivation of algae. All these applications are described in considerable detail by experts who have personally conducted research in the particular field concerned, and together the papers give a compi'ehensive picture of the present position. It is perhaps the future possibilities that will most interest the general reader. Economics is the controlling factor, and careful design is necessary to reduce the equipment to the most simple form. The introduction of new materials and methods of construction will greatly reduce the capital cost of equipment. Applications are mostly limited to regions of high solar radiation, and in such localities solar energy could be integrated with existing forms of energy supply. The greatest scope lies in countries which are located in lat. $20^{\circ}-40^{\circ}$ N. and S., and which are at present industrially undeveloped. Solar energy must in the future fulfil an essential need in such areas as development and research proceed.

The promoters of the Symposium are to be congratulated on producing in a relatively short time a volume which is very well printed and clearly illus. trated, and which comprises so much interesting information on the subject.

H. HEYwOOD

\section{NUCLEAR ENGINEERING}

\section{Principles of Nuclear Reactor Engineering}

By Samuel Glasstone. Pp. ix +861 . (London : Macmillan and Co., Ltd., 1956.) 60s. net.

THE earlier work, "The Elements of Nuclear Reactor Theory", in which Dr. S. Glasstone collaborated with Dr. M. K. Edlund, has become a standard text-book for the rapidly growing number of nuclear reactor engineers. To say that my immediate reaction to this newer work by Dr. Glasstone was one of disappointment is not to belittle the book, which is the most complete of its kind yet published. It is aimed particularly at "the practising engineer who wishes to know something of the impact of nuclear energy on his professional activities" and "students in engineering schools at the senior or first year graduate levels". The difficulties in catering for the two classes of reader in the same book are apparent in the text.

After a 57-page summary of the scope of the book, three chapters are devoted to basic nuclear physics and reactor theory. Thanks to a more concise treatment of slowing-down theory, and to the omission of much of a purely mathematical nature, the contents of the earlier book have been compressed with perhaps some gain in lucidity. Enough theoretical and experimental information is now available on fast reactor theory to warrant a much fuller discussion than is given. Wisely the terms 'geometrical buckling' and 'material buckling' have been omitted, as has also (perhaps unwisely) the 'track length' explanation of the misnomer 'neutron flux'. Thero is an excellent discussion of the effects of variation of lattice parameter.

The chapters on instrumentation and coritrol are very clearly written, though in a book of this scope perhaps the automatic control of reactor systems should be accorded greater importance. Actinide chemistry is dealt with at some length in tho chapter on fuel processing and is followed by a discussion of the principles of chemical separation. The build-up of higher isotopes in a reactor justifies a much more comprehensive treatment than it receives hore. In 